1 Postprint of Journal of Functional Foods Volume 40, January 2018,

2 Pages 400-407 DOI: 10.1016/j.jff.2017.11.030

\title{
$5 \quad$ In vitro digestion of chlorophyll pigments from edible seaweeds
}

6 Kewei Chen, María Roca*

7 Food Phytochemistry Department, Instituto de la Grasa, Consejo Superior de Investigaciones

8 Científicas (CSIC). University Campus Pablo de Olavide, Building 46, Carretera de Utrera km. 1, 9 Sevilla 41013, Spain.

$10 *$ Corresponding author

11 e-mail: covichen@hotmail.com, mroca@ig.csic.es

12 Telephone: +00 34 954.61.15.50

13 Fax: +00 34954.61 .67 .90

15 Abstract

16 The three most common edible seaweeds, Nori (Porphyra umbilicalis), Sea Lettuce (Ulva

17 sp.) and Kombu (Laminaria ochroleuca), were subjected for the first time to an in vitro digestion 18 process in order to study the digestive stability and recovery of chlorophyll pigments of the $a, b$ 19 and $c$ series. Due to the complex and diverse chlorophyll profile in these seaweeds, new 20 principles regarding the behaviour of chlorophylls during the in vitro digestion were obtained. 
21 Thus, the in vitro digestion conditions favoured the pheophytinisation reaction of the $a$ series in 22 comparison with the $b$ and $c$ series; oxidation reactions were promoted for chlorophylls instead 23 of pheophorbides and pheophytins; the conversion of pheophytin to pheophorbide was observed 24 for the first time during in vitro digestion and only occurred when the initial chlorophyll profile 25 contained a large proportion of pheophytins. The extracellular matrix of the seaweeds was the 26 main determining factor in the recovery of pigments after in vitro digestion, with significant 27 differences between seaweed species. The novel chlorophyll behaviour observed for digestive, 28 stability and recovery patterns obtained in the present work are applicable to other food matrices. 29 Keywords: Bioavailability, chlorophyll, in vitro digestion, Kombu, Nori, Sea lettuce, seaweeds. 


\section{Introduction}

Chlorophyll pigments, which allow plant species to convert light into biological energy,

32 are the most abundant pigments on earth and exhibit a variety of biological actions (Roca, Chen,

33 \& Pérez-Gálvez, 2016), such as an antimutagenic effect (Simonich et al., 2007), antigenotoxic

34 properties (Negishi, Rai, \& Hayatsu, 1997), and a potent antioxidant capacity to scavenge free

35 radicals, preventing lipid oxidation (Lanfer-Marquez, Barros, \& Sinnecker, 2005). Additionally, natural chlorophyll pigments deriving from marine algae exhibit other potential health benefits,

37 such as neuroprotective (Ina, Hayashi, Nozaki, \& Kamei, 2007) and anti-inflammatory features 38 (Henderson \& Kincaid, 1997). Despite the fact that chlorophyll is abundant in our diet, the available information about the digestive process of chlorophyll pigments is limited. This may be

40 due to the fact that chlorophyll pigments are very sensitive to the environmental changes and 41 prone to chemical and enzymatic changes (Schwartz \& Lorenzo, 2006). Consequently, there was 42 an assumption in the past that chlorophyll pigments could not be absorbed by the human body.

43 However, since Egner et al., (2000) described copper chlorin e4 and chlorin e4 ethyl ester in 44 human serum, research began on the bioavailability of chlorophyll pigments. The assumed 45 mechanism of chlorophyll absorption proposed by Ferruzzi and Blakeslee (2007) follows similar routes to those observed for other xenobiotic compounds that require (a) efficient release of the

47 chlorophyll from the food matrix, (b) stability for gastric and small intestinal digestive conditions, (c) solubilisation of lipophilic derivatives (micellization), (d) uptake by small intestinal 49 absorptive epithelial cells, and (e) secretion into circulation (basal transport). Consequently, the first step for the large-scale research of nutrient absorption (Garrett,

51 Failla, \& Sarama, 1999) is to establish the efficiency of bioaccessibility, defined as the amount of 52 the ingested compound that is transferred during digestion from the food matrix to the micelles, 
measured through in vitro digestion protocols. Information on the bioaccessibility of chlorophyll

54 derivatives is scarce and limited to higher food matrix plants, such as spinach leaves (Ferruzzi, 55 Failla, \& Schwartz, 2001) or pea purée (Gallardo-Guerrero, Gandul-Rojas, \& Mínguez56 Mosquera, 2008), where the chlorophyll profile is narrow: mainly chlorophyll $a$ and $b$ in the 57 initial material with only tiny amounts of pheophytin $a$ and pheophytin $b$. Finally, a study has 58 been performed with several chlorophyll standards (Gandul-Rojas, Gallardo-Guerrero, \& 59 Mínguez-Mosquera, 2009) including chlorophyll $a(b)$, pheophytin $a(b)$, pyropheophytin $a$, 60 pheophorbide $a$ and pyropheophorbide $a$. It has been shown that de-esterification of phytol 61 makes chlorophyll pigments more bioaccessible. This suggests the need to extend the research of 62 the digestion process of chlorophyll pigments to a wider range of chlorophyll derivatives in a 63 food matrix. Marine algae or seaweeds, which have been traditionally consumed in Asian diets since ancient times, have gained popularity in European countries (Taboada, Millán, \& Míguez, 2010).

66 Currently, it is widely accepted that seaweeds are rich in vitamins, minerals, dietary fibre and 67 other functional nutrients that can provide a necessary supplement to the modern diet, which 68 mainly consists of refined food ingredients (Ferraces-Casais, Lage-Yusty, Rodríguez-Bernaldo 69 de Quirós, \& López-Hernández, 2012). Since the discovery of the many beneficial compounds 70 present in algae, much effort has been expended in examining their nutritional aspects, including 71 bioaccessibility of micronutrients such as iodine and carotenoid (Granado-Lorencio et al., 2009), 72 and the overall nutritional effects on tested animals (Taboada, Millán, \& Míguez, 2010). 73 However, no reports were found associated with the digestive behaviour of chlorophyll pigments

74 from seaweeds, even though it has already been discovered that content of marine algae is 75 extremely high in these pigments and indeed the profile is very extensive (Pangestuti \& Kim, 
2011; Chen, Ríos, Pérez-Gálvez, \& Roca, 2017).

In this study, the three most consumed seaweeds were selected for an in vitro digestion process, including Nori, Sea Lettuce and Kombu. These three species are representative of the three different classes of algae including the red, green and brown kinds, which are Rhodophytes, Chlorophytes and Phaeophytes, respectively. The aim of the study was to analyse the influence of different food matrices on the bioaccessibility of chlorophylls, as the different classes of algae show very different extracellular matrix features (Synytsya, Čopíková, Kim, \& Yong, 2015). In addition, these materials provide unique, complex and complete chlorophyll profiles that allow a systematic approach to digestive properties. Nori contains only $a$ series chlorophyll, Sea Lettuce contains $a$ and $b$ series, and Kombu, $a$ and $c$ series (Ferraces-Casais, Lage-Yusty, RodríguezBernaldo de Quirós, \& López-Hernández, 2012; Chen, Ríos, Pérez-Gálvez, \& Roca, 2017). Indeed, seaweeds contain a large amount of dephytylated chlorophyll such as pheophorbide (Ferraces-Casais, Lage-Yusty, Rodríguez-Bernaldo de Quirós, \& López-Hernández, 2012), magnesium-free chlorophyll such as pheophytin and its oxidised derivatives (Koseki, Muranaka, Sakai, \& Nakajima, 2002) as well as chlorophyll $a$ and $b$. This allows a comparison to be made between different structures of chlorophyll related to their digestive behaviour and the effect of food matrices from different seaweed species during the digestive metabolism.

\section{Materials and methods}

All the following procedures were carried out under green light to avoid the photooxidation of chlorophyll pigments.

\subsection{Raw material.}

Sea Lettuce (Ulva sp.) was provided by Suralgae (Cádiz, Spain) while Nori (Porphyra umbilicales) and Kombu (Laminaria ochroleuca) were provided by Algamar (Pontevedra, 
99 Spain). The three seaweed species were collected on the Atlantic littoral region on the south

100

101

102

103

104

105

106

107

108

109

110

111

112

113

114

115

116

117

118

119

120

western part (Cádiz) and the north western part (Pontevedra) of Spain. The dried material (25$45^{\circ} \mathrm{C}$ for $30-45$ hours) is supplied in vacuum sealed bags.

\subsection{Chemicals and reagents}

Sunflower oil was purchased in a local supermarket. $\alpha$-Amylase (porcine pancreas, VI-B), pepsin (porcine), bile extract (porcine), lipase pancreatic (porcine), sodium chloride, sodium bicarbonate, tetrabutylammonium acetate and ammonium acetate (98\%) were supplied by Sigma-Aldrich Chemical Co. (Madrid, Spain). Pancreatin (porcine) was provided by Fluka (Zwijndrecht, The Netherlands). Other reagents (acetone, potassium chloride, calcium chloride, analysis grade) were supplied by Teknokroma (Barcelona, Spain). $N, N$-dimethylformamide (DMF) PAR grade and LC/MS grade solvents and water were supplied by Panreac (Barcelona, Spain), while acetone HPLC grade was supplied by Merck. The deionized water used was obtained from a Milli-Q 50 system (Millipore Corp., Milford, MA, USA).

\subsection{Sample preparation}

To warranty the consistency of each sample for the independent in vitro digestion, samples of seaweeds were prepared according to the following procedure. Amounts of fresh dried seaweeds (15 g for Nori and Kombu, $7.5 \mathrm{~g}$ for Sea Lettuce) were weighed and combined with saline solution $\left(140 \mathrm{mM} \mathrm{NaCl}, 5 \mathrm{mM} \mathrm{KCl}\right.$ and $\left.6 \mathrm{mM} \mathrm{CaCl}_{2}\right)$ in a ratio of 1:20(w/v). The mixture was homogenized to obtain the consistent puree. Aliquots corresponding to ca. $0.1 \mathrm{~g}$ of fresh dried seaweeds for Sea Lettuce and ca. $0.2 \mathrm{~g}$ for Nori and Kombu were blanketed with nitrogen and stored at $-20^{\circ} \mathrm{C}$ before used.

\subsection{In vitro digestion}


122 Gandul-Rojas, \& Mínguez-Mosquera (2008) with some modifications. Samples were subjected

123 to the oral, gastric and intestinal phase of digestion to reproduce the physiological process.

124 Initially, $80 \mu \mathrm{L}$ of sunflower oil free of chlorophyll pigments was added into the defrosted 125 sample to achieve the requirement of food matrix in daily intake (around $4 \%$ of the fresh wet 126 weight of seaweeds). The three digestive mixtures were incubated in a water bath $\left(37^{\circ} \mathrm{C}\right)$ where 127 the samples were horizontally shaken at constant rate $(85 \mathrm{rpm})$ for the oral (10 min), gastric $(1 \mathrm{~h})$ 128 and intestinal $(2 \mathrm{~h})$ phase. From the first phase, the simulated saliva was obtained by dissolving $129 \alpha$-amylase (2041 U/g fresh wet weight of raw material) in saline solution $(140 \mathrm{mM} \mathrm{NaCl}, 5 \mathrm{mM}$ $130 \mathrm{KCl}, \mathrm{pH}$ 7.0). The gastric phase was initiated by adding saline solution to reach a final 131 concentration of $2.4 \mathrm{mg} / \mathrm{mL}$ pepsin and adjusting the $\mathrm{pH}$ to 2.0 by adding some drops of $0.1 \mathrm{M}$ $132 \mathrm{HCl}$. Subsequently, the $\mathrm{pH}$ was adjusted to 6.0 by adding $\mathrm{NaHCO}_{3}(0.9 \mathrm{M})$ to initiate the 133 intestinal phase including bile salts $(2.4 \mathrm{mg} / \mathrm{mL})$, pancreatin $(0.4 \mathrm{mg} / \mathrm{mL})$ and lipase $(0.2 \mathrm{mg} / \mathrm{mL})$ 134 dissolved in $\mathrm{NaHCO}_{3}(0.1 \mathrm{M})$ solution. The final volume of the digesta was around $35 \mathrm{~mL}$. 135 Reactions were stopped by placing tubes in ice bath and aliquots $(2 \times 5 \mathrm{~mL})$ of digesta were 136 collected. All the samples were blanketed with nitrogen and placed at $-20^{\circ} \mathrm{C}$ until analysis.

\section{$137 \quad 2.5$ Pigment extraction}

138 The raw fresh dried seaweeds were grinded with liquid nitrogen and passed through 576 139 meshes $/ \mathrm{cm}^{2}$ sieves (particle size equivalent to $0.5 \mathrm{~mm}(\Phi)$ ), and the moisture content was 140 measured. 0.2 grams of seaweed powder were extracted with $30 \mathrm{~mL}$ of DMF:water (9:1), vortex 141 mixed $(10 \mathrm{~s})$, centrifuged $(6000 \mathrm{rpm}, 3 \mathrm{~min})$, filtrated (nylon, $0.22 \mu \mathrm{m})$ and stored at $-20^{\circ} \mathrm{C}$ until 142 HPLC analysis (Chen, Ríos, Pérez-Gálvez, \& Roca, 2017).

143 The digesta samples were lyophilized (Virtis, Benchtop K) before pigment extraction. 
144 Then, $200 \mu \mathrm{L}$ distilled water was added to soften the porous residue and the mixture was shaken 145 for 5 min. Additional $200 \mu \mathrm{L}$ of DMF was added to the mixture and shacked again 5 min. Next, $1461.6 \mathrm{~mL}$ acetone was added and the mixture immersed in an ultrasonic bath (10 min, $720 \mathrm{~W})$. The 147 solvent layer after filtration was directly analyzed by HPLC.

\subsection{Pigment identification and quantification by HPLC-UV-Visible}

The pigments were separated by reversed-phase HPLC using a Hewlett-Packard HP 1100 liquid chromatograph. A Mediterranea Sea1 8 column $(200 \times 4.6 \mathrm{~mm}, 3 \mu \mathrm{m}$ particle size $)$ was used (Teknokroma, Barcelona, Spain) protected by a guard column $(10 \times 4.6 \mathrm{~mm})$ packed with the same material. Separation was performed using the elution gradient described by Roca, GandulRojas, \& Mínguez-Mosquera (2007) with the mobiles phases: A, water/ion pair reagent/methanol

$154(1 / 1 / 8, \mathrm{v} / \mathrm{v} / \mathrm{v})$ and $\mathrm{B}$, methanol/acetone $(1 / 1, \mathrm{v} / \mathrm{v})$. The ion pair reagent was $0.05 \mathrm{M}$ tetrabutylammonium and $1 \mathrm{M}$ ammonium acetate in water. The on-line UV-visible spectra were recorded from 350 to $800 \mathrm{~nm}$ with the photodiode-array detector and sequential detection was performed at 410, 430, 450 and $666 \mathrm{~nm}$. Data were collected and processed with a LC HP ChemStation (Rev.A.05.04). Identification of chlorophyll derivatives was made based on co159 chromatography with authentic samples (previously identified by MS/MS) and from their spectral characteristics (Chen, Ríos, Pérez-Gálvez \& Roca, 2015; Chen, Ríos, Roca \& Pérez-

161 Gálvez, 2015), except for oxidized pheophorbide $c$, which identification is tentative only based 162 in spectroscopic and chromatographic characteristics (Jeffrey \& Wright, 1987). Quantification of 163 pigments was performed with the corresponding calibration curves (amount versus integrated 164 peak area). The calibration equations were obtained by least-squares linear regression analysis over a concentration range according to the observed levels of these pigments in the analysed

166 samples, obtaining $\mathrm{R}^{2}$ values always higher than 0.9997. Duplicate injections were made for five 
167 different volumes at each standard solution.

168

\subsection{Statistical analysis}

For comparison and measurement of the significant differences on the in vitro digestion procedure, a minimum of 4 independent digestions were made for each sample, and each digesta was analysed for pigment content in duplicate. Percentage of chlorophyll recovery in digesta was calculated as nanograms in digesta $\times 100$ / nanograms in the starting material used for digestion. Differences were compared by one-way analysis of variance (ANOVA, StatSoft, Inc., 2001) with student's $t$-test as test for comparison. Differences were considered significant at $P$ values $<0.05$.

\section{Results and discussion}

\subsection{Chlorophyll structures present in seaweeds}

Fig. 1 illustrates all the structures and names of chlorophyll derivatives found in the three edible seaweeds, Nori, Sea Lettuce and Kombu. Different phyla contain different chlorophyll series. Rhodophyta plastids (Nori) have phycobiliproteins and chlorophyll $a$ derivatives, with the characteristic methyl group at $\mathrm{C} 7\left(\mathrm{R}_{1}\right.$ in Fig. 1). Chlorophyta plastids (Sea Lettuce) in addition to $a$ series also contain chlorophyll $b$ derivatives, with the formyl group at $\mathrm{C} 7\left(\mathrm{R}_{1}\right.$ in Fig. 1$)$. And finally, Phaeophyta plastids (Kombu) contain chlorophyll derivatives of the $c$ series, which mostly contain an acrylic acid side chain at C17 and they are not usually esterified, in addition to the chlorophyll a series. Seaweeds belonging to Chlorophyta phylum contain mainly chlorophylls (Chen, Ríos, Pérez-Gálvez, \& Roca, 2017) while the photosynthetic apparatus of seaweeds from Rhodophyta and Phaeophyta phylum is formed mainly from pheophytins (chlorophylls with the central magnesium substituted by hydrogens, $R_{5}$ at Fig. 1) and pheophorbides (de-metalled chlorophylls de-esterified at $\mathrm{C} 17^{3}$, Fig. 1) (Ferraces-Casais, LageYusty, Rodríguez-Bernaldo de Quirós, \& López-Hernández, 2012). However, the complete 
190 characterisation of the chlorophyll profile in seaweeds has only been performed recently (Chen,

191 Ríos, Pérez-Gálvez, \& Roca, 2017), describing chlorophyll derivatives with different oxidation

192 degrees. In this sense, several enzymatic activities have been proposed as being responsible for

193 hydroxylation at $\mathrm{C} 13^{2}$, yielding the $13^{2}$-hydroxy derivatives $\left(\mathrm{R}_{2}\right.$ in Fig. 1$)$. A second structural

194 feature described in the chlorophyll profile of seaweeds (Chen, Ríos, Pérez-Gálvez, \& Roca,

195 2017) is the rearrangement of the isocyclic ring, establishing a lactone group (Fig. 1, structure B),

196 the $15^{1}$-hydroxy-lactone derivatives $\left(15^{1}\right.$-hydroxy-lactone chlorophylls, $15^{1}$-hydroxy-lactone

197 pheophorbides and $15^{1}$-hydroxy-lactone pheophytins). A different oxidation process that also

198 involves the isocyclic ring is the formation of the purpurin-18 derivatives (Fig. 1, structure D),

199 with the characteristic cyclic anhydride. This catabolite is a product of the enzymatic oxidative

200 transformation during senescence (Ma \& Dolphin, 1996). Finally, pyropheophytin $a$ is formed by

201 the loss of the carboxymethoxy group at $\mathrm{C} 13^{2}$ probably due to the pheophorbidase enzyme (Shioi,

202 2006). Seaweeds certainly represent an ideal raw material for studying the structural stability of

203 chlorophyll compounds, not only because of the high variety of chlorophyll derivatives at

204 different oxidative statuses, but also due to the different quantitative and proportional content of

205 them among different phyla.

$206 \quad 3.2$ Stability of chlorophyll pigments during in vitro digestion

207 Table 1 shows the modifications of each chlorophyll pigment in Nori, Sea Lettuce and

208 Kombu, while Table 2 shows the modifications of the chlorophyll series, as a consequence of the

209 oral, gastric and intestinal in vitro digestion. Numerous factors affect chlorophyll structures

210 during digestion, mainly $\mathrm{pH}$, the oxidative environment and enzymatic reactions.

The seaweed Nori, being a Rhodophyta phylum, only contains chlorophyll $a$ series

212 derivatives and consequently structural changes of the chlorophyll pigments develop within the $a$ 
213 series (Tables 1-2). The chlorophyll profile is quite particular, presenting 60\% of pheophytin 214 derivatives, $37 \%$ of pheophorbide-related compounds and less than $2 \%$ of chlorophylls (Chen, 215 Rios, Pérez-Gálvez, \& Roca, 2017). In the fresh dried Nori, chlorophyll $a$ is completely 216 transformed into pheophytin $a$ during digestion because of the acidic environment in the gastric 217 phase. Another significant change is the formation of $15^{1}$-hydroxy-lactone pheophorbide $a$ after 218 digestion; nevertheless, a small increase in $15^{1}$-hydroxy-lactone pheophytin $a$ content is also 219 observed, derived from the oxidising ambient attained during the digestive process that favoured 220 isocyclic ring oxidation. In line with this observation, a slight increase can be observed for $13^{2}$ 221 hydroxy pheophorbide $a$ in all the samples after digestion, which correlates again with an 222 increase in the oxidative environment during in vitro digestion. Pyropheophytin $a$ and purpurin$22318 a$ series were degraded to some extent during simulated digestion, and purpurin-18- $a$ is 224 completely degraded. The in vitro digestion of the fresh and dried Nori sample produced a 225 significant increase in pheophorbide $a(15 \%)$ and conversely decreased the percentage of 226 pheophytin $a(12 \%)$. This means that pheophytin is partially transformed into pheophorbide 227 during in vitro digestion by the loss of the phytol chain.

The green seaweeds (Sea Lettuce) contain both chlorophyll $a$ and $b$ series, introducing a new variable in the study, and the relative proportions of chlorophyll derivatives is also different. 230 Thus, most of the content is chlorophyll (74\%), while pheophytins (19\%) and pheophorbides $231(7 \%)$ are lower contributors to the pigment profile. After in vitro digestion, relatively high 232 percentages of chlorophyll $a(43 \%)$ and chlorophyll $b(24 \%)$ were observed, and a fraction of 233 chlorophyll $a$ plus $13^{2}$-hydroxy-chlorophyll $a$ was entirely transformed (into pheophytin $a$ and $23413^{2}$-hydroxy pheophytin $a$ ), while chlorophyll $b$ is more steady in the digestion environment with 235 the same percentage (14\%) remaining in the digesta. Conversion from chlorophyll $a$ to 
236 pheophytin $a$ is also associated with chlorophyll $a$ degradation to non-coloured derivatives, so 237 that the $a / b$ ratio decreased from 2.97 to 1.87 , as the degradative reaction does not take place for 238 the $b$ series. It is interesting that no significant increase after digestion was observed for the 239 pheophorbide compounds present in fresh material as observed in the Nori seaweed samples. 240 Calculation of total oxidised derivatives $\left(13^{2}\right.$-hydroxy pheophytin $a, 13^{2}$-hydroxy chlorophyll $b$ 241 and $13^{2}$-hydroxy pheophytin $b$ ) that were quantified as $13^{2}$-hydroxy derivatives experienced a 242 great increase after the digestion process, which means that oxidative reactions in the digestion 243 process were favoured. The conversion reactions from $13^{2}$-hydroxy chlorophyll $a$ and $13^{2}$ 244 hydroxy chlorophyll $b$ to $13^{2}$-hydroxy pheophytin $a$ and $13^{2}$-hydroxy chlorophyll $b$, respectively 245 cannot explain that increase sufficiently. The percentage content of $15^{1}$-hydroxy-lactone 246 chlorophylls, including $15^{1}$-hydroxy-lactone pheophorbide $a, 15^{1}$-hydroxy-lactone pheophytin $a$ 247 and $15^{1}$-hydroxy-lactone chlorophyll $b$ is similar before and after the digestion process. 248 Purpurin-18 $a$ derivatives are also prone to degradation in Sea Lettuce as they were completely 249 degraded during the in vitro digestion.

Kombu, the brown algae contains both chlorophyll $a$ and $c$ series and a profile fashioned 251 by pheophytin (68\%), pheophorbides (5\%) and chlorophylls (27\%) (Chen, Rios, Pérez-Gálvez, 252 \& Roca, 2017). The digestion of Kombu samples implies the complete transformation of 253 chlorophyll $a$ series derivatives, as observed in the other seaweeds. Chlorophyll $c$ is more 254 resistant to digestion; although a portion of the original compound is transformed into 255 pheophorbides, some amount (3\%) is still present in the final digesta as the original chlorophyll $c$. 256 The absence of the phytol chain in the structural arrangement of chlorophyll $c$ (Fig. 1) facilitates 257 the conversion between chlorophyll $c$ and pheophorbide $c$ by just the removal of the magnesium 258 atom in the centre of the pyrrole ring, a process easily afforded in the acidic conditions of 
259 digestion. Thus, the digestion of Kombu samples produced a proportional conversion of 260 chlorophyll $c$ to pheophorbides. And following the same outline as observed for the Nori sample, 261 the main modification during the digestion of Kombu is the significant increase in the percentage 262 of pheophorbide $a$, from $5 \%$ to $23 \%$, a concomitant process with the decrease of pheophytin $a$, 263 from $55 \%$ to $45 \%$. In addition, the presence of $15^{1}$-hydroxy-lactone pheophorbide $a$ is detected 264 after digestion, as observed in Nori samples. Once again, the transformation of chlorophyll $a$ to 265 pheophytin $a$, due to the magnesium dechelation process, cannot explain the decline of 266 pheophytin $a$. As denoted for Nori samples, some amounts of pheophytin $a$ are degraded to 267 pheophorbide $a$. Finally, the percentages of oxidised derivatives significantly rise, mainly due to 268 the outstanding presence of oxidised pheophorbide $c$. The content of the rest of the chlorophyll 269 derivatives is maintained at levels similar to starting levels, except for purpurin-18- $a$ derivatives, 270 which are completely degraded. In summary, the in vitro digestion in brown seaweeds implies 271 the modification in the ratio of pheophorbide to pheophytin, from 5:68 to $36: 61$, the total 272 depletion of chlorophyll $a$, the loss of most of chlorophyll $c$, and an enhanced level of oxidised 273 chlorophyll derivatives.

274 In general, the reactions that change the chlorophyll profile are the same for the three 275 seaweeds (pheophytinisation, "pheophorbidation" and oxidation), but the intensity of the 276 transformation depends on the initial characteristic chlorophyll profile of each type of seaweed. 277 The low $\mathrm{pH}$ conditions that govern the gastric digestion phase caused the transformation of 278 chlorophylls to their corresponding magnesium-free derivatives. Among the green chlorophylls 279 including chlorophyll $a, b$, and $c$ and their $13^{2}$-hydroxy or $15^{1}$-hydroxy-lactone counterparts, 280 chlorophyll $a, 13^{2}$-hydroxy chlorophyll $a$ and $15^{1}$-hydroxy-lactone chlorophyll $a$ are the most 281 prone to pheophytinisation since they are totally transformed after the digestion process. Most of 
282 the other two series of chlorophyll (chlorophyll $b, 13^{2}$-hydroxy chlorophyll $b, 15^{1}$-hydroxy283 lactone chlorophyll $b$ and chlorophyll $c$ ) are also converted to their corresponding magnesium284 free derivatives, while small amounts are still present in the final digesta.

285 The comparison of these results with chlorophyll behaviour during digestion in different 286 food matrices only concerns chlorophylls of series $a$ and $b$ as previous studies performed the in 287 vitro digestion with plant species. While the complete pheophytinisation is reported for 288 chlorophylls in spinach puree (Ferruzzi, Failla, \& Schwartz, 2001), allomerised chlorophyll $b$ 289 was resistant to digestion in fresh peas (Gallardo-Guerrero, Gandul-Rojas, \& Mínguez-Mosquera, 290 2008). A clear resistance of chlorophyll $b$ to digestion has only been observed (Gandul-Rojas, 291 Gallardo-Guerrero, \& Mínguez-Mosquera, 2009) with an oily mixture of chlorophyll $a$ and 292 chlorophyll $b$ standards. These reports point to the higher stability of chlorophyll $b$ than 293 chlorophyll $a$ due to the presence of the formyl group at C7 site (Fig. 1), which should have 294 some incidence in the pheophytinisation process during digestion process. It has been widely 295 observed that chlorophyll $a$ transformation to pheophytin $a$ is faster than for chlorophyll $b, 2.5-9$ 296 fold according to different reports (Lajollo, Tannenbaum, \& Labuza, 2010). Although 297 theoretically, the exchange of magnesium for protons in the chlorophyll molecule is energetically 298 favoured (Kania et al., 2014), the reactivity is not only associated with the porphyrin macrocycle 299 but also with the constitution of the peripheral groups. Chlorophyll $a$ and $b$ share the same 300 macrocycle arrangement and only the coupling of the formyl group at the $\mathrm{C} 7$ position with the $\pi$ 301 electron system of the porphyrin ring in chlorophyll $b$ is different. This group exerts an electron 302 withdrawal effect that makes the core nitrogens in the macrocycle less susceptible to an 303 electrophilic attack in comparison with the effect of the methyl group at $\mathrm{C} 7$ in chlorophyll $a$ 304 (Mazaki, Watanabe, Takahashi, Struck, \& Scheer, 1992). 
This is the first time that the chemical behaviour of chlorophyll $c$ during in vitro digestion has been reported. The chlorophyll $c$ identified in Kombu is chlorophyll $c_{1}$, which does not present the phytol chain. Conversion to a magnesium-free derivative is not affected by the steric hindrance between the $\mathrm{C} 17$ chain and the $\beta$-keto ester group (accounted for in dephytylated chlorophyll structures) (Schanderl \& Chichester, 1962), such that other structural arrangements should be reasonable causes. Chlorophyll $c_{1}$ shows a different unsaturation arrangement in the porphyrin macrocycle with different $\mathrm{C}=\mathrm{C}$ and $\mathrm{C}=\mathrm{N}$ locations in comparison with $a$ or $b$ series (structure C, Fig. 1), combined with the additional double bond between $\mathrm{C} 17^{1}$ and $\mathrm{C} 17^{2}$, making the chlorophyll molecule less flexible and fully conjugative (Shishkin, 1997). Thus, the $\pi$ electron density in the planar porphyrin ring of the chlorophyll $c_{1}$ molecule is decreased by the higher tendency of electron withdrawal to the double bond at $\mathrm{C} 17^{1}$, and it makes the molecule more stable than chlorophyll $a$ (Mazaki, Watanabe, Takahashi, Struck, \& Scheer, 1992).

The second major modification that occurs during in vitro digestion is the transformation of pheophytins to pheophorbides, which means the loss of the phytyl chain at $\mathrm{C} 17^{3}$ (Fig. 1). Although it is accepted that pheophytin could be dephytylated to pheophorbide under strong acid treatment (Sievers \& Hynninen, 1977), no significant increase of the pheophorbide content was observed after in vitro digestion of spinach purée (Ferruzzi, Failla, \& Schwartz, 2001), peas (Gallardo-Guerrero, Gandul-Rojas, \& Mínguez-Mosquera, 2008) and pure standard of pheophytin (Gandul-Rojas, Gallardo-Guerrero, \& Mínguez-Mosquera, 2009). In this study, a significant increase in the pheophorbide proportion was observed in the samples of Nori and Kombu after digestion but not in the Sea Lettuce samples. The "pheophorbidation" reaction (pheophytin is dephytylated to pheophorbide) does not significantly occur in Sea Lettuce because the chlorophyll profile of this seaweed contains large amounts of green chlorophylls (chlorophyll 

342 stated.

$a$ or $b$ ), and, in acidic conditions, the dechelation reaction is the first one to take place (Sievers \& Hynninen, 1977). Consequently, the transformation processes in the acidic environment is dominated by the pheophytinisation reaction during the in vitro digestion of Sea Lettuce, and there was no increase in the pheophorbide proportion in the fresh dried sample. Actually, the chlorophyll profile of Sea Lettuce is very similar to the green plant species previously used, spinach purée and peas (Ferruzzi, Failla, \& Schwartz, 2001; Gallardo-Guerrero, Gandul-Rojas, \& Mínguez-Mosquera, 2008), where the increase in the pheophorbide proportion is not obvious as observed in green seaweed. Chlorophyll $a$ or $b$ are prone to transformation into pheophytin $a$ or $b$ in the acidic environment, thus preventing pheophytin from de-esterification into pheophorbide. Consequently, in those seaweeds where most of the initial chlorophyll derivatives are pheophytins (Nori and Kombu), the yield of pheophorbide from pheophytin increases after the digestion process. The only report that performed in vitro digestion with the pheophytin $a$ standard (Gandul-Rojas, Gallardo-Guerrero, \& Mínguez-Mosquera, 2009), dissolved that pigment in oil and consequently it was protected from digestion to some degree, as the authors

Oxidised reactions are observed during the digestion process, since a variety of oxidative derivatives $\left(13^{2}\right.$-hydroxy and $15^{1}$-hydroxy-lactone) are found to increase in percentage or appear in the final digesta. Previous results have shown one-off increases in allomerised chlorophylls and pheophytins during digestion explained with different hypotheses, either enzymatic activity, such as peroxidase (Ferruzzi, Failla, \& Schwartz, 2001; Gallardo-Guerrero, Gandul-Rojas, \& Mínguez-Mosquera, 2008), or due to chemical origin (Gandul-Rojas, Gallardo-Guerrero, \& Mínguez-Mosquera, 2009). Our results show that the oxidative process is unselective, yielding, after digestion, $13^{2}$-hydroxy and $15^{1}$-hydroxy-lactone derivatives of chlorophylls, pheophytins, 
351 pheophorbides and occurring in a similar way to the $a, b$ and $c$ series. This result is consistent

352 with a purely chemical origin of the oxidative reactions. Likewise, oxidation reactions were also

353 observed for other phytochemical compounds such as dietary vitamin and carotenoids during the

354 in vitro digestion process (Rodríguez-Roque, Rojas-Graü, Elez-Martínez, \& Martín-Belloso,

355 2013). In addition, the wide distribution of chlorophyll derivatives in the initial digestive

356 seaweeds allows the comparison of the behaviour of magnesium-containing derivatives

357 (chlorophyll) and magnesium-free ones (pheophytin and pheophorbide) through the oxidative

358 reactions. The highest increases of $13^{2}$-hydroxy derivatives during the in vitro digestion are for

359 Sea Lettuce (9\%) mainly observed for $13^{2}$-hydroxy-pheophytin $a$ and $13^{2}$-hydroxy-pheophytin $b$,

360 and for Kombu (8\%), mainly observed for oxidised pheophorbide $c$. The initial chlorophyll

361 profile consists of large amount of magnesium-containing chlorophylls, so it could be inferred

362 that for magnesium-containing chlorophylls (chlorophyll $a$, chlorophyll $b$ and chlorophyll $c$ ) the

363 oxidisation reactions are promoted in comparison with the pheophynisation, and then oxidised

364 derivatives were pheophytinised. It is difficult to develop a theory to explain such results

365 considering the different reaction mechanisms that may take place. For oxidation reactions, the

366 main limiting factors is the generation of reactive oxygen species that induce allomerisation

367 (Gandul-Rojas \& Mínguez-Mosquera, 1996), while pheophytinisation reactions mainly depend

368 on the $\mathrm{pH}$ value of the environment (Gunawan \& Barringer, 2000). Indeed, the magnesium

369 chelation in the centre of the macrocycle could increase the ability to donate electrons from the

370 conjugated porphyrin system, such that metal-chelated chlorophyll derivatives also show a

371 stronger antioxidant ability (Ferruzzi, Böhm, Courtney, \& Schwartz, 2002). This may explain the

372 preference of the oxidative process by chlorophylls instead of pheophytin. 
Finally, the chemical conditions reached during the in vitro digestion completely degrade

374 the purpurin-18 $a$ derivatives in the three species tested, probably due the characteristic

375 configuration of the isocyclic ring that confers a major liability to this structure towards

376 nucleophilic reactions (Wang, Yin, \& Yang, 2013).

$377 \quad 3.3$ Recovery rate of chlorophyll derivatives from fresh dried seaweeds after in vitro

378 digestion

379

The recovery rate is measured by the content of chlorophyll pigments in the digesta with respect to the initial chlorophyll content of the starting seaweed material. This index is expressed as a percentage and allows the determination of the extension of the degradative reactions that transform chlorophylls into non-coloured products, and the effect of the food matrix on the release of food nutrients. Fig. 2 shows the recovery rate of the chlorophyll derivatives in the three seaweeds.

The recovery rate of the $a$ series in Nori samples, represents the recovery rate of the total chlorophyll content. In the fresh dried material of Nori, the recovery rate of chlorophyll is $c a$. $38774 \%$, a result significantly higher than the values observed in Sea Lettuce and Kombu, regarding 388 both the $a$ series and total chlorophyll recovery rates. The green algae Sea Lettuce has 389 chlorophylls of $a$ and $b$ series and the recovery rate of total chlorophyll is around $37 \%$. The 390 recovery rate of the $a$ series is significantly lower than the $b$ series, because some fraction of the 391 chlorophyll $a$ content is degraded during the in vitro digestion, at higher levels than chlorophyll $b$, 392 as shown by $a / b$ ratio values before and after digestion (Table 2). Consequently, chlorophylls of $393 b$ series are more resistant to digestion and their recovery rate is higher. Kombu mainly contains 394 chlorophylls of the $a$ and $c$ series and according to the recovery values depicted in Fig. 2, both 395 series show similar stability during the digestion process. The fresh dried Kombu sample 

417 and carboxylic polysaccharides called fucoidans and alginates, respectively. These highly 418 branched polysaccharides may interact with proteins, polymeric phenolics, metal cations and

The percentages of recovery rates of chlorophyll of Nori and Sea Lettuce are similar to the observed values in peas (60-87\%, Gallardo-Guerrero, Gandul-Rojas, \& Mínguez-Mosquera, 2008) and in an oily mixture of chlorophyll standards (50-82\%, Gandul-Rojas, GallardoGuerrero, \& Mínguez-Mosquera, 2009). The loss of chlorophyll pigments during in vitro digestion may be due to the activity of peroxidase and lipoxygenase, which contributes to degrading chlorophyll pigments, as stated previously (Gallardo-Guerrero, Gandul-Rojas, \& Mínguez-Mosquera, 2008) since peroxidase (Murthy, Sharma, \& Rao, 1988) and lipoxygenase (Kuo, Hwang, Hsu, \& Pan, 1996) has been identified to be widely distributed in seaweed. However, Kombu shows lower recovery rate values compared with those data showing that differences in the food matrix are significant contributors for the different releases of chlorophyll pigments. Despite the fact that marine algae generally contain large amounts of amorphous embedding matrix polysaccharides in their cell walls (Wehr \& Sheath, 2003; Davis), there are many differences related with polysaccharide components and distribution among Rhodophyta, Chlorophyta and Phaeophyta. Red algae contain composite cell walls made of cellulose, xylan, or mannan fibrils and sulphated galactans such as agars and carrageenans; green algae also present various sulphated and/or carboxylic polysaccharides with a specific structure in cell walls, such as ulvans and sulphated glycans (Synytsya, Čopíková, Kim, \& Yong, 2015). Indeed, the cell walls of brown algae contain cellulose fibrils that consist of highly branched sulphated heteropolysaccharides (xyloglucans, xylofucoglucuronans, etc.) and special sorts of sulphated 
419 other molecules making the cell walls of brown algae rigid and stable (Synytsya, Čopíková, Kim,

420 \& Yong, 2015). Compared with Nori (red algae) and Sea Lettuce (green algae), Kombu (brown

421 algae) is extensively filamentous, multicellular, complex and has additional mucus cavity

422 (Kumar, 2009), which makes the access of digestion enzymes more difficult for the release of

423 chlorophyll pigments, leading to the lowest recovery rate values being observed in Kombu.

424 4. Conclusions

425 The diverse and complex chlorophyll profile of edible seaweeds allowed the study of

426 different digestive behaviour of chlorophyll derivatives with different structural arrangements.

427 During the in vitro digestion process, chlorophylls of the $a$ series are more prone to

428 pheophytinisation than $b$ and $c$ series chlorophylls; oxidation reactions commonly occur in the

429 digestion process and have a preference for chlorophylls rather than pheophytins; the 430 "pheophorbidation" reaction was first observed in the digestion of Nori and Kombu seaweeds as 431 they provided large amounts of pheophytins and small amounts of chlorophylls in the initial 432 materials. And it is assumed that oxidation reactions took place more easily for metal-chelated 433 chlorophylls than for metal-dechelated pheophorbides or pheophytins. According to the recovery 434 rate values, it is clear that the extracellular matrix of the seaweeds is a determinant factor for the 435 recovery rate of chlorophylls after simulated digestion. The results suggest that both the chemical 436 structure of phytochemicals and the nature of the food matrix are decisive for the digestive 437 stability and recovery of chlorophylls after in vitro digestion.

438 Acknowledgements

439 This work was supported by the Comisión Interministerial de Ciencia y Tecnología 440 (CICYT-EU, Spanish and European Government, AGL 2015-63890-R).

\section{$441 \quad$ References}


442 Chen, K., Ríos, J. J., Pérez-Gálvez, A., \& Roca, M. (2015a). Development of an accurate and 443 high-throughput methodology for structural comprehension of chlorophylls derivatives. (I) 444 phytylated derivatives. Journal of Chromatography A, 1406, 99-108. 445 DOI:10.1016/j.chroma.2015.05.072

446 Chen, K., Ríos, J. J., Roca, M., \& Pérez-Gálvez, A. (2015b). Development of an accurate and 447 high-throughput methodology for structural comprehension of chlorophylls derivatives. (II) 448 dephytylated derivatives. Journal of Chromatography A, 1406, 90. 449 DOI:10.1016/j.chroma.2015.08.007

450 Chen, K., Ríos, J. J., Pérez-Gálvez, A., \& Roca, M. (2017). Comprehensive chlorophyll 451 composition in the main edible seaweeds. Food Chemistry, 228, 625-633. DOI: $452 \quad$ 10.1016/j.foodchem.2017.02.036

453 Egner, P. A., Stansbury, K. H., Snyder, E. P., Rogers, M. E., Hintz, P. A., \& Kensler, T. W. 454 (2000). Identification and characterization of chlorin $e_{4}$ ethyl ester in sera of individuals 455 participating in the chlorophyllin chemoprevention trial. Chemical Research in 456 Toxicology, 13(9), 900-906. DOI:10.1021/tx000069k

457 Ferraces-Casais, P., Lage-Yusty, M. A., Rodríguez-Bernaldo de Quirós, A., \& López458 Hernández, J. (2012). Evaluation of bioactive compounds in fresh edible seaweeds. Food 459 Analytical Methods, 5(4), 828-834. DOI:10.1007/s12161-011-9321-2

460 Ferruzzi, M. G., Failla, M. L., \& Schwartz, S. J. (2001). Assessment of degradation and intestinal 461 cell uptake of carotenoids and chlorophyll derivatives from spinach puree using an in vitro 
462 digestion and Caco-2 human cell model. Journal of Agricultural \& Food Chemistry, 49(4), 2082-

463 2089. DOI:10.1021/jf000775r

464 Ferruzzi, M. G., Böhm, V., Courtney, P. D., \& Schwartz, S. J. (2002). Antioxidant and 465 antimutagenic activity of dietary chlorophyll derivatives determined by radical scavenging and 466 bacterial reverse mutagenesis assays. Journal of Food Science, 67(7), 2589-2595.

467 DOI:10.1111/j.1365-2621.2002.tb08782.x

468 Ferruzzi, M. G., \& Blakeslee, J. (2007). Digestion, absorption, and cancer preventative activity 469 of dietary chlorophyll derivatives. Nutrition Research, 27(1), 1-12.

$470 \quad$ DOI:10.1016/j.nutres.2006.12.003

471 Gallardo-Guerrero, L., Gandul-Rojas, B., \& Mínguez-Mosquera, M. I. (2008). Digestive 472 stability, micellarization, and uptake by Caco-2 human intestinal cell of chlorophyll derivatives 473 from different preparations of pea (Pisum sativum L.). Journal of Agricultural \& Food 474 Chemistry, 56(18), 8379-8386. DOI:10.1021/jf8013684

475 Gandul-Rojas, B., \& Mínguez-Mosquera, M. I. (1996). Chlorophyll and carotenoid composition 476 in virgin olive oils from various Spanish olive varieties. Journal of the Science of Food \& 477 Agriculture, 72(1), 31-39. DOI:10.1002/(SICI)1097-0010(199609)72:1<31::AID$478 \quad$ JSFA619>3.0.CO;2-5

479 Gandul-Rojas, B., Gallardo-Guerrero, L., \& Mínguez-Mosquera, M. I. (2009). Influence of the 480 chlorophyll pigment structure on its transfer from an oily food matrix to intestinal epithelium 481 cells. Journal of Agricultural \& Food Chemistry, 57(12), 5306-5314. DOI:10.1021/jf900426h 
482 Garrett, D. A., Failla, M. L., \& Sarama, R. J. (1999). Development of an in vitro digestion 483 method to assess carotenoid bioavailability from meals. Journal of Agricultural \& Food 484 Chemistry, 47(10), 4301-4309. DOI:10.1021/jf9903298

485 Granado-Lorencio, F., Herrero-Barbudo, C., Acién-Fernández, G., Molina-Grima, E., Fernández486 Sevilla, J. M., Pérez-Sacristán, B., \& Blanco-Navarro, I. (2009). In vitro bioaccesibility of lutein 487 and zeaxanthin from the microalgae Scenedesmus almeriensis. Food Chemistry, 114(2), 747-752. 488 DOI:10.1016/j.foodchem.2008.10.058

489 Gunawan, M. I., \& Barringer, S. A. (2000). Green color degradation of blanched broccoli 490 (Brassica oleracea) due to acid and microbial growth. Journal of Food Processing \& 491 Preservation, 24(3), 253-263. DOI:10.1111/j.1745-4549.2000.tb00417.x

492 Henderson, K., \& Kincaid, D. (1997). Potent anti-inflammatory activity of pheophytin $a$ derived 493 from edible green alga, Enteromorpha prolifera (sujiao-nori). International Journal of 494 Immunopharmacology, 19(6), 355-358. DOI: 10.1016/S0192-0561(97)00070-2

495 Ina, A., Hayashi, K., Nozaki, H., \& Kamei, Y. (2007). Pheophytin $a$, a low molecular weight 496 compound found in the marine brown alga Sargassum fulvellum, promotes the differentiation of 497 pc12 cells. International Journal of Developmental Neuroscience, 25(1), 63-68. 498 DOI:10.1016/j.ijdevneu.2006.09.323

499 Jeffrey, S. W., \& Wright, S. W. (1987). A new spectrally distinct component in preparations of 500 chlorophyll $c$, from the micro-alga Emiliania huxleyi, (Prymnesiophycease). Biochimica et 501 Biophysica Acta (BBA) - Bioenergetics, 894(2), 180-188. DOI:10.1016/0005-2728(87)90188-5 
502 Kania, A., Pilch, M., Rutkowskazbik, D., Susz, A., Heriyanto, Stochel, G., \& Fiedor, L. (2014).

503 High-pressure and theoretical studies reveal significant differences in the electronic structure and 504 bonding of magnesium, zinc, and nickel ions in metalloporphyrinoids. Inorganic 505 Chemistry, 53(16), 8473-8484. DOI: 10.1021/ic501029b

506 Koseki, S., Muranaka, C., Sakai, T., \& Nakajima, H. (2002). Preparation of allomerized products 507 of chlorophyll molecules from salted kombu. Bulletin of the Japanese Society of Scientific 508 Fisheries, 68(1), 78-84.

509 Kuo, J. M., Hwang, A., Hsu, H. H., \& Pan, B. S. (1996). Preliminary identification of 510 lipoxygenase in algae (Enteromorpha intestinalis) for aroma formation. Journal of Agricultural 511 \& Food Chemistry, 44(8), 2073-2077. DOI:10.1021/jf950774c

512 Lajollo, F., Tannenbaum, S. R., \& Labuza, T. P. (2010). Reaction at limited water concentration. 513 2. Chlorophyll degradation. Journal of Food Science, 36(6), 850-853. DOI:10.1111/j.1365$514 \quad 2621.1971 . t b 15542 . x$

515 Lanfer-Marquez, U. M., Barros, R. M. C., \& Sinnecker, P. (2005). Antioxidant activity of 516 chlorophylls and their derivatives. Food Research International, 38(8), 885-891. 517 DOI:10.1016/j.foodres.2005.02.012

518 Ma, L., \& Dolphin, D. (1996). Stereoselective synthesis of new chlorophyll a related 519 antioxidants isolated from marine organisms. Journal of Organic Chemistry, 61(7), 2501-2510. 520 DOI:10.1021/jo951854i 
521 Mazaki, H., Watanabe, T., Takahashi, T., Struck, A., \& Scheer, H. (1992). Epimerization of 522 chlorophyll derivatives. V. effects of the central magnesium and ring substituents on the 523 epimerization of chlorophyll derivatives. Bulletin of the Chemical Society of Japan, 65(11), 524 3080-3087. DOI:10.1246/bcsj.65.3080

525 Murthy, M. S., Sharma, C. L. N. S., \& Rao, Y. N. (1988). Salinity induced changes in peroxidase 526 activity in the green seaweed Ulva lactuca. Botanica Marina,31(4), 307-310. 527 DOI:10.1515/botm.1988.31.4.307

528 Negishi, T., Rai, H., \& Hayatsu, H. (1997). Antigenotoxic activity of natural 529 chlorophylls. Mutation Research/fundamental \& Molecular Mechanisms of Mutagenesis, 376(1530 2), 97-100. DOI:10.1016/S0027-5107(97)00030-4

531 Pangestuti, R., \& Kim, S. K. (2011). Biological activities and health benefit effects of natural 532 pigments derived from marine algae. Journal of Functional Foods, 3(4), 255-266. 533 DOI:10.1016/j.jff.2011.07.001

534 Roca, M., Gandul-Rojas, B., \& Mínguez-Mosquera, M. I. (2007). Varietal differences in 535 catabolic intermediates of chlorophylls in Olea europaea, (L.) fruit cvs. Arbequina and 536 Blanqueta. Postharvest Biology $\quad \& \quad$ Technology, 44(2), $\quad 150-156$. 537 DOI:10.1016/j.postharvbio.2006.12.001

538 Roca, M., Chen, K., \& Pérez-Gálvez, A. (2016). Chlorophylls. In R. Carle, \& R. M. Schweiggert 539 (Eds.), Handbook on natural pigments in food and beverages: industrial applications for 540 improving food color. (pp. 125-158). Woodhead Publishing. DOI:10.1016/B978-0-08-100371$541 \quad 8.00006-3$ 
542 Rodríguez-Roque, M. J., Rojas-Graü, M. A., Elez-Martínez, P., \& Martín-Belloso, O. (2013).

543 Changes in vitamin $c$, phenolic, and carotenoid profiles throughout in vitro gastrointestinal

544 digestion of a blended fruit juice. Journal of Agricultural \& Food Chemistry, 61(8), 1859-1867.

545 DOI:10.1021/jf3044204

546 Schwartz, S. J., \& Lorenzo, T. V. (2006). Chlorophyll stability during continuous aseptic

547 processing and storage. Journal of Food Science, 56(4), 1059-1062. DOI:10.1111/j.1365-

$548 \quad 2621.1991 . t b 14641 . \mathrm{X}$

549 Sievers, G., \& Hynninen, P. H. (1977). Thin-layer chromatography of chlorophylls and their

550 derivatives on cellulose layers. Journal of Chromatography, 134(2), 359-364. DOI:

$551 \quad 10.1016 / \mathrm{S} 0021-9673(00) 88534-9$

552 Simonich, M. T., Egner, P. A., Roebuck, B. D., Orner, G. A., Jubert, C., Pereira, C., Groopman, J.

553 D., Kensler, T. W., Dashwood, R. H., Williams, D. E., \& Bailey, G. S. (2007). Natural

554 chlorophyll inhibits aflatoxin $b_{1}$-induced multi-organ carcinogenesis in the

555 rat. Carcinogenesis, 28(6), 1294-1302. DOI:10.1093/carcin/bgm027

556 Shishkin, O. V. (1997). Conformational flexibility of six-membered 1,4-dihydrocycles. Journal

557 of Molecular Structure, 412(1), 115-120. DOI:10.1016/S0022-2860(97)00004-5

558 Shioi, Y. (2006). Characterization and cloning of the chlorophyll-degrading enzyme 559 pheophorbidase from cotyledons of radish. Plant Physiology, 140(2), 716-725.

560 DOI:10.1104/pp.105.071290 
561 Synytsya, A., Čopíková, J., Kim, W. J., \& Yong, I. P. (2015). Cell wall polysaccharides of

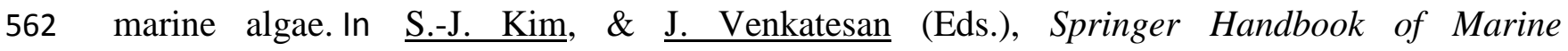
563 Biotechnology. (pp. 543-590). Berlin Heidelberg: Springer. DOI:10.1007/978-3-642-53971-8_22

564 Taboada, C., Millán, R., \& Míguez, I. (2010). Composition, nutritional aspects and effect on 565 serum parameters of marine algae Ulva rigida. Journal of the Science of Food \& 566 Agriculture, 90(3), 445-449. DOI:10.1002/jsfa.3836

567 Wang, J. J., Yin, Y. F., \& Yang, Z. (2013). Synthesis of purpurin-18 imide derivatives from 568 chlorophyll $a$, and $b$, by modifications and functionalizations along their peripheries. Journal of 569 the Iranian Chemical Society, 10(3), 583-591. DOI:10.1007/s13738-012-0194-0

570 Wehr, J. D, \& Sheath, R. G. (2003). Freshwater algae of North America. San Diego: Academic 571 Press. pp. 757-773.

572 Zhao, X., Jiao, G., Wu, J., Zhang, J., \& Yu, G. (2015). Laminaria japonica, Aresch. and 573 Ecklonia kurome, Okam. 昆布 (Kunbu, kelp). In Y. Liu, Z. Wang, \& J. Zhang (Eds.), Dietary 574 Chinese Herbs (pp. 767-779). Vienna: Springer. DOI:10.1007/978-3-211-99448-1_86

575

576 
Table 1: Quantitative distribution (percentage) of individual chlorophyll pigments in fresh dried Nori, Sea Lettuce and Kombu seaweeds previous (pre-d) and posterior (post-d) to in vitro digestion (means $\pm \mathrm{SE}$ ).

\begin{tabular}{|c|c|c|c|c|c|c|}
\hline & \multicolumn{2}{|c|}{ Nori } & \multicolumn{2}{|c|}{ Sea Lettuce } & \multicolumn{2}{|c|}{ Kombu } \\
\hline & pre-d & post-d & pre-d & post-d & pre-d & post-d \\
\hline Chlorophyll $a$ & $1,81 \pm 0,15$ & & $43,41 \pm 0,33$ & & $7,21 \pm 0,22$ & \\
\hline $13^{2}$-hydroxy chlorophyll $a$ & & & $5,14 \pm 0,38$ & & & \\
\hline $15^{1}-\mathrm{OH}$-lact. chlorophyll $a^{\mathrm{a}}$ & & & & & $2,41 \pm 0,11$ & \\
\hline Pheophorbide $a$ & $35,70 \pm 4,04$ & $48,30 \pm 2,70$ & $4,57 \pm 0,10$ & $3,58 \pm 0,37$ & $4,63 \pm 0,46$ & $22,57 \pm 3,70$ \\
\hline $13^{2}$-hydroxy pheophorbide $a$ & $1,60 \pm 0,24$ & $3,82 \pm 0,67$ & $2,10 \pm 0,01$ & $2,77 \pm 0,29$ & $0,44 \pm 0,17$ & $1,26 \pm 0,11$ \\
\hline $15^{1}$-OH-lact. pheophorbide $a$ & & $0,43 \pm 0,10$ & $0,29 \pm 0,01$ & $0,17 \pm 0,05$ & & $0,53 \pm 0,38$ \\
\hline Purpurin-18 $a$ & $0,19 \pm 0,04$ & & & & & \\
\hline Pheophytin $a$ & $44,85 \pm 2,58$ & $32,97 \pm 1,18$ & $11,35 \pm 0,03$ & $42,87 \pm 0,37$ & $54,98 \pm 0,02$ & $45,25 \pm 6,71$ \\
\hline $13^{2}$-hydroxy pheophytin $a$ & $8,24 \pm 1,30$ & $7,80 \pm 0,63$ & $6,64 \pm 0,52$ & $14,85 \pm 0,33$ & $11,80 \pm 0,25$ & $13,39 \pm 1,53$ \\
\hline $15^{1}-\mathrm{OH}$-lact. pheophytin $a$ & $1,24 \pm 0,11$ & $2,83 \pm 1,15$ & $1,16 \pm 0,37$ & $0,93 \pm 0,08$ & $1,19 \pm 0,01$ & $1,53 \pm 0,17$ \\
\hline Pyropheophytin $a$ & $5,81 \pm 0,37$ & $3,42 \pm 0,38$ & & & $0,32 \pm 0,01$ & $1,00 \pm 0,33$ \\
\hline Phytyl purpurin-18 $a$ & $0,56 \pm 0,05$ & $0,45 \pm 0,18$ & $0,15 \pm 0,00$ & & $0,34 \pm 0,05$ & \\
\hline Chlorophyll $b$ & & & $23,67 \pm 0,61$ & $14,47 \pm 0,20$ & & \\
\hline $13^{2}$-hydroxy chlorophyll $b$ & & & $1,23 \pm 0,21$ & $2,15 \pm 0,05$ & & \\
\hline $15^{1}$-OH-lact. chlorophyll $b$ & & & $0,30 \pm 0,12$ & $0,95 \pm 0,12$ & & \\
\hline Pheophytin $b$ & & & & $13,15 \pm 0,14$ & & \\
\hline $13^{2}$-hydroxy pheophytin $b$ & & & & $4,10 \pm 0,14$ & & \\
\hline Chlorophyll $c$ & & & & & $16,68 \pm 0,92$ & $2,85 \pm 0,79$ \\
\hline Pheophorbide $c$ & & & & & & $5,57 \pm 1,81$ \\
\hline Oxidized pheophorbide $c$ & & & & & & $6,05 \pm 1,40$ \\
\hline
\end{tabular}

${ }^{\mathrm{a}} 15^{1}$-OH-lact.: $15^{1}$-hydroxy-lactone. 
Table 2: Quantitative distribution (percentage) of chlorophyll pigments in fresh dried Nori, Sea Lettuce and Kombu seaweeds previous (pre-d) and posterior (post-d) to in vitro digestion (means \pm SE).

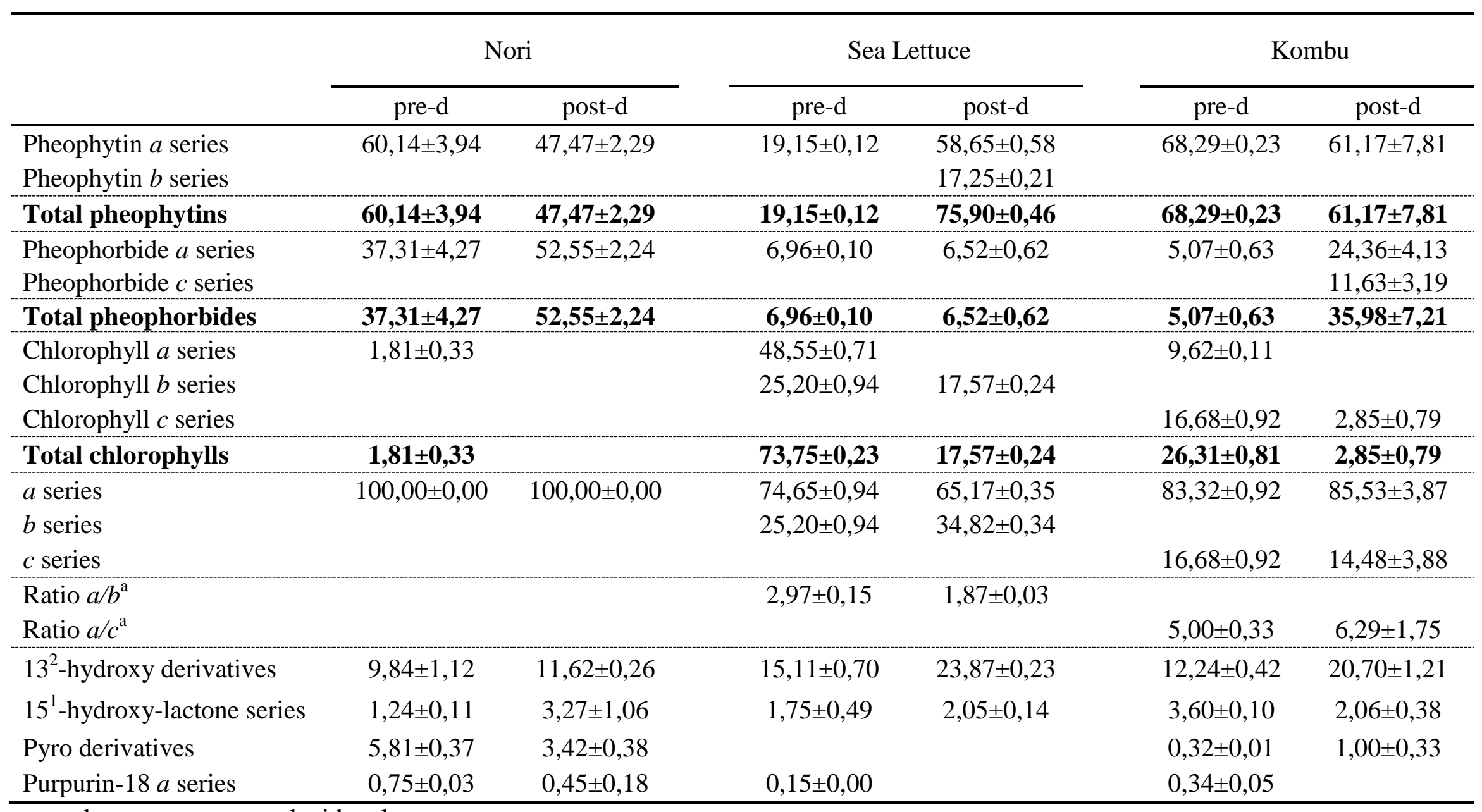

a, numbers were expressed with values. 

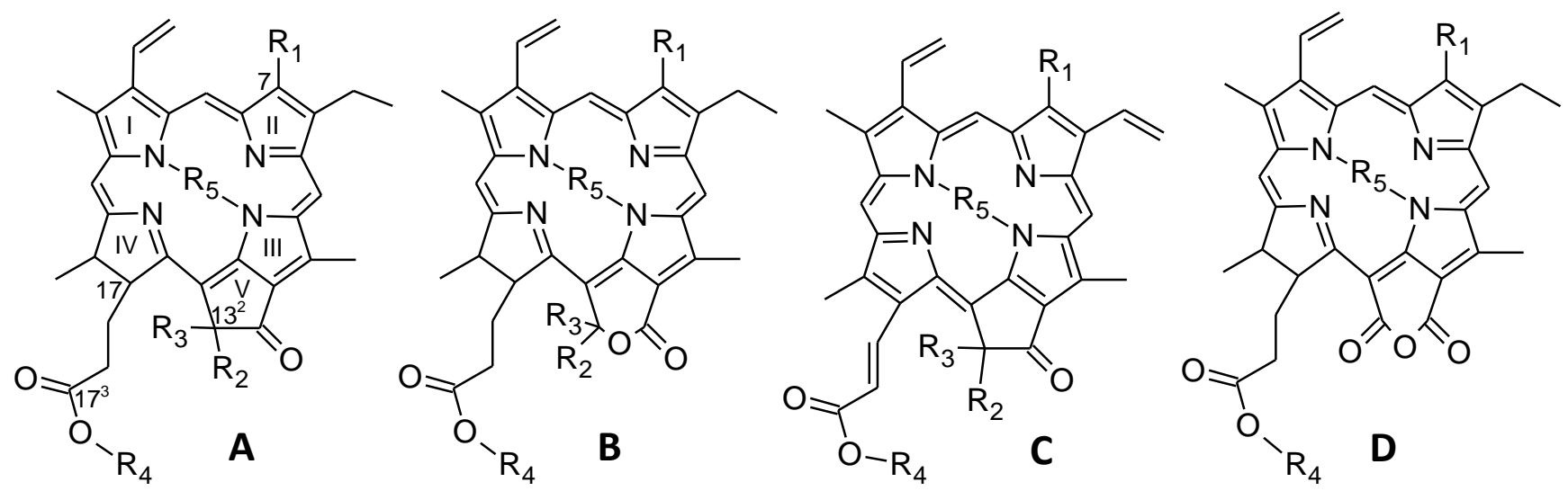

\begin{tabular}{|c|c|c|c|c|c|c|}
\hline Compound & Structure & $\mathrm{R}_{1}$ & $\mathrm{R}_{2}$ & $\mathrm{R}_{3}$ & $\mathrm{R}_{4}$ & $\mathrm{R}_{5}$ \\
\hline \multicolumn{7}{|c|}{ Series $a$} \\
\hline Chlorophyll $a$ & A & $\mathrm{CH}_{3}$ & $\mathrm{H}$ & $\mathrm{COOCH}_{3}$ & phytyl & $\mathrm{Mg}$ \\
\hline $13^{2}$-hydroxy chlorophyll $a$ & A & $\mathrm{CH}_{3}$ & $\mathrm{OH}$ & $\mathrm{COOCH}_{3}$ & phytyl & $\mathrm{Mg}$ \\
\hline $15^{1}$-hydroxy-lactone chlorophyll $a$ & B & $\mathrm{CH}_{3}$ & $\mathrm{OH}$ & $\left(15^{2}\right) \mathrm{COOCH}_{3}$ & phytyl & $\mathrm{Mg}$ \\
\hline Pheophorbide $a$ & A & $\mathrm{CH}_{3}$ & $\mathrm{H}$ & $\mathrm{COOCH}_{3}$ & $\mathrm{H}$ & $2 \mathrm{H}$ \\
\hline $13^{2}$-hydroxy pheophorbide $a$ & A & $\mathrm{CH}_{3}$ & $\mathrm{OH}$ & $\mathrm{COOCH}_{3}$ & $\mathrm{H}$ & $2 \mathrm{H}$ \\
\hline $15^{1}$-hydroxy-lactone pheophorbide $a$ & B & $\mathrm{CH}_{3}$ & $\mathrm{OH}$ & $\left(15^{2}\right) \mathrm{COOCH}_{3}$ & $\mathrm{H}$ & $2 \mathrm{H}$ \\
\hline Purpurin-18 $a$ & $\mathrm{D}$ & $\mathrm{CH}_{3}$ & - & - & $\mathrm{H}$ & $2 \mathrm{H}$ \\
\hline Pheophytin $a$ & A & $\mathrm{CH}_{3}$ & $\mathrm{H}$ & $\mathrm{COOCH}_{3}$ & phytyl & $2 \mathrm{H}$ \\
\hline $13^{2}$-hydroxy pheophytin $a$ & A & $\mathrm{CH}_{3}$ & $\mathrm{OH}$ & $\mathrm{COOCH}_{3}$ & phytyl & $2 \mathrm{H}$ \\
\hline $15^{1}$-hydroxy-lactone pheophytin $a$ & B & $\mathrm{CH}_{3}$ & $\mathrm{OH}$ & $\left(15^{2}\right) \mathrm{COOCH}_{3}$ & phytyl & $2 \mathrm{H}$ \\
\hline Pyropheophytin $a$ & A & $\mathrm{CH}_{3}$ & $\mathrm{H}$ & $\mathrm{H}$ & phytyl & $2 \mathrm{H}$ \\
\hline Phytyl purpurin-18 $a$ & $\mathrm{D}$ & $\mathrm{CH}_{3}$ & - & - & phytyl & $2 \mathrm{H}$ \\
\hline \multicolumn{7}{|c|}{ Series $b$} \\
\hline Chlorophyll $b$ & A & $\mathrm{CHO}$ & $\mathrm{H}$ & $\mathrm{COOCH}_{3}$ & phytyl & $\mathrm{Mg}$ \\
\hline $13^{2}$-hydroxy chlorophyll $b$ & A & $\mathrm{CHO}$ & $\mathrm{OH}$ & $\mathrm{COOCH}_{3}$ & phytyl & $\mathrm{Mg}$ \\
\hline $15^{1}$-hydroxy-lactone chlorophyll $b$ & B & $\mathrm{CHO}$ & $\mathrm{OH}$ & $\left(15^{2}\right) \mathrm{COOCH}_{3}$ & phytyl & $\mathrm{Mg}$ \\
\hline \multicolumn{7}{|c|}{ Series $c$} \\
\hline Chlorophyll $c_{1}$ & $\mathrm{C}$ & $\mathrm{CH}_{3}$ & $\mathrm{H}$ & $\mathrm{COOCH}_{3}$ & $\mathrm{H}$ & $\mathrm{Mg}$ \\
\hline
\end{tabular}

Fig. 1: Names and structures of chlorophyll derivatives found in the fresh dried Nori, Sea Lettuce and Kombu seaweeds. 


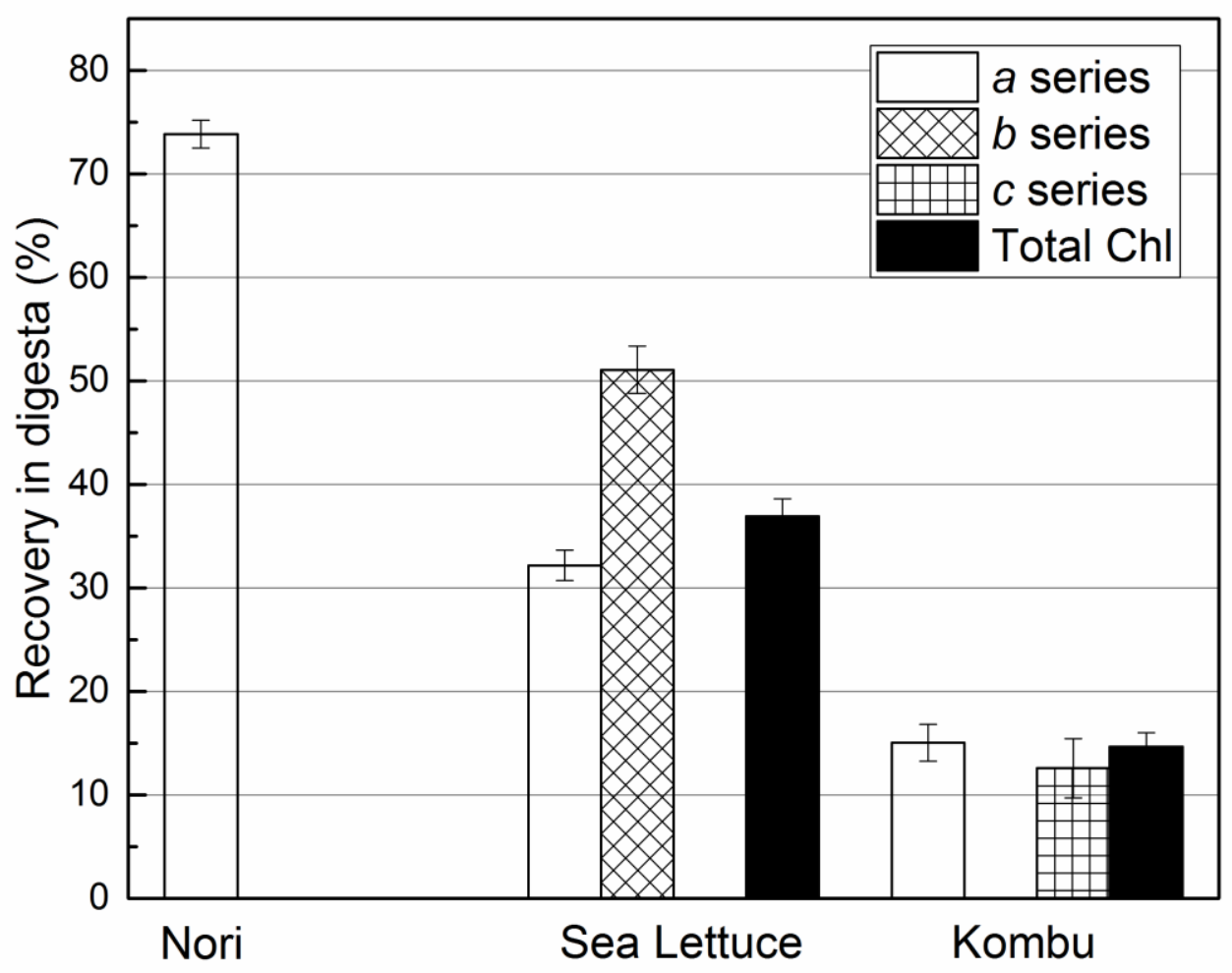

Fig. 2: Recovery of chlorophyll derivatives from tested Nori, Sea Lettuce and Kombu seaweeds after in vitro digestion. Total Chl stands for total chlorophylls. Data represent mean \pm SEM for 8 independent measurements. Nori contains $a$ series; Sea Lettuce contains $a$ and $b$ series; Kombu contains $a$ and $c$ series. 